\title{
METODE PENGUKURAN ALIRAN AIR TANAH DI LAHAN GAMBUT
}

\author{
Muhammad Agung Pribadi ${ }^{1}$, Sigit Sutikno ${ }^{1,2^{*}}$, Koichi Yamamoto ${ }^{3}$ \\ ${ }^{1}$ Jurusan Teknik Sipil, Universitas Riau, Pekanbaru, Indonesia, 28293 \\ ${ }^{2}$ Pusat Studi Bencana (PSB), Universitas Riau, Pekanbaru, Indonesia, 28293 \\ ${ }^{3}$ Civil and Environmental Department, Yamaguchi University, Yamaguchi, Japan \\ Email : muhammad.agung6149@student.unri.ac.id, sigit.sutikno@lecturer.unri.ac.id, k_yama@yamaguchi-

$$
\text { u.ac.jp }
$$

\begin{abstract}
ABSTRAK
Provinsi Riau yang memiliki lahan gambut lebih dari $60 \%$ dari total lahan gambut yang terdapat di Pulau Sumatera. Di Provinsi Riau, Kabupaten Bengkalis salah satu wilayah yang penyebaran lahan yang terluas kedua setelah kabupaten Indragiri. Kabupaten Bengkalis yang terdiri dari wilayah daratan dan pulau, yang mana wilayah pulau tersebut memiliki lahan gambut lebih dari $80 \%$ dari total keseluruhan luas pulau. Pulau bengkalis telah mengalami fenomena - fenomena yang terjadi seperti abrasi, subsidensi, dan kebakaran lahan. Abrasi yang terjadi di Pulau Bengkalis bagian Barat Laut telah berlangsung lebih dari 30 tahun terakhir membuat penelitian ini bagaimana situasi hidrologis yang terjadi akibat fenomena abrasi ini. Penelitian ini bertujuan untuk mengetahui bagaimana aliran air tanah di pinggir pantai abrasi dengan menggunakan alat PDV (Paper Disk Velocimeter). Alat PDV ini merupakan pengukuran kecepatan aliran air tanah yang dikembangkan di Universitas Yamaguchi, Jepang. Alat ini sangat sederhana dan ekonomis jika dibandingkan alat lain yang cenderung rumit dan mahal.
\end{abstract}

Kata Kunci : Gambut, Abrasi, Aliran Air Tanah, PDV (Paper Disk Velocimeter)

\section{ABSTRACT}

Riau Province which has peatlands of more than $60 \%$ of the total peatland on the island of Sumatra. In Riau Province, Bengkalis Regency is one of the areas with the second largest land distribution after Indragiri Regency. Bengkalis Regency which consists of land and island areas, where the island area has peatlands of more than $80 \%$ of the total area of the island. Bengkalis Island has experienced phenomena such as abrasion, subsidence, and land fires. The abrasion that occurred in the Northwestern part of Bengkalis Island has been going on for more than 30 years, making this study how the hydrological situation that occurs due to this abrasion phenomenon. This study aims to determine how groundwater flows along the abrasion coast using a PDV (Paper Disk Velocimeter) tool. This PDV tool is a groundwater flow velocity measurement developed at Yamaguchi University, Japan. This tool is very simple and economical when compared to other tools which tend to be complicated and expensive.

Keywords : Peat, Abration, Groundwater Flow, PDV (Paper Disk Velocimeter) 


\section{PENDAHULUAN}

Luas lahan gambut di Indonesia merupakan salah satu wilayah gambut tropis terluas di dunia sekitar 14,95 juta hektar yang tersebar di berbagai wilayah [1]. Penyebaran yang terbesar terletak di Pulau Sumatera, terkhusus Provinsi Riau. Potensi lahan gambut yang terdapat di Riau sangat besar. Sehingga perlu adanya penelitian - penelitian lebih lanjut bagaimana fenomena - fenomena yang terjadi di lahan gambut itu sendiri.

Tanah gambut yang terbentuk akibat pembusukan vegetasi, membuat tanah gambut ini mengandung kandungan organik yang tinggi dan dapat menyimpan air dalam jumlah besar [2]. Bahkan, tanah gambut dapat menyimpan air hingga lebih dari masa tanahnya itu sendiri. Kondisi ini yang mengakibatkan pergerakan aliran air tanah cukup intensif terjadi.

Air tanah yang berasal dari mata air tanah ataupun air hujan yang turun ke permukaan tanah akibat adanya gravitasi. Setelah turunnya hujan, air akan bergerak turun (infiltrasi) dan juga bergerak secara kapiler (berbagai arah) [3]. Sifat air tanah ini yang menarik untuk dilakukan penelitian bagaimana aliran air tanah yang terjadi di sisi barat laut Pulau Bengkalis yang sering terdampak akibat fenomena abrasi pantai. Pemilihan lokasi di Pulau Bengkalis karena terdapat lebih dari $80 \%$ dari wilayah merupakan lahan gambut (Gambar 1).

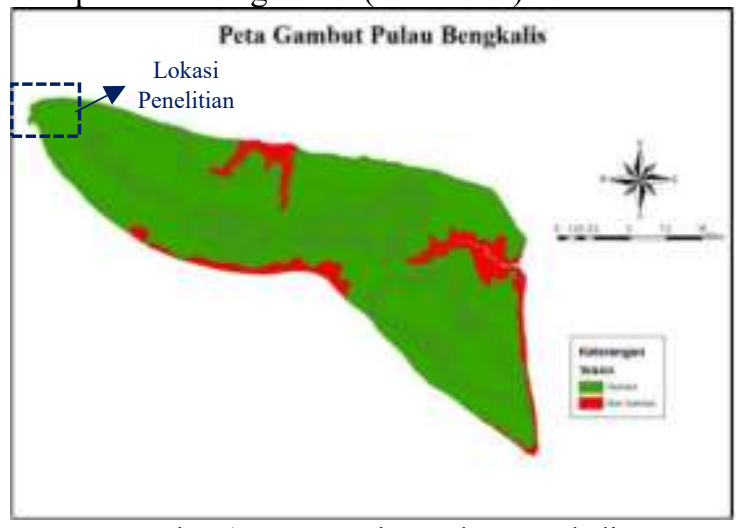

Gambar 1. Peta Gambut Pulau Bengkalis Sumber : [2]

Dalam melakukan penelitian aliran air tanah di Pulau Bengkalis ini, digunakan alat PDV (Paper Disk Velocimeter) yang dikembangkan oleh Prof. Koichi Yamamoto dari Universitas Yamaguchi, Jepang. Sebelumnya pernah dilakukan penelitian yang sama oleh S Sutikno, Ramawilis, Hutapea, Rinaldi, \& Yamamoto (2020) dengan lokasi gambut dengan titik - titik tinjau sekitar kanal di Desa Lukun, Kepulauan Meranti Riau. Alat ini terdiri dari beberapa rangkaian bahan seperti tiang, spons, sensor, dan kertas yang dibuat dari Maruman Company $126,5 \mathrm{~g} / \mathrm{m}^{2}$ dan tinta hitam: Canon BCl-6BK. Hasil penelitian ini adalah analisis aliran air tanah dengan menggunakan metode pengukuran dengan PDV yang sederhana dan ekonomis. Gambar alat dapat dilihat pada Gambar 2.

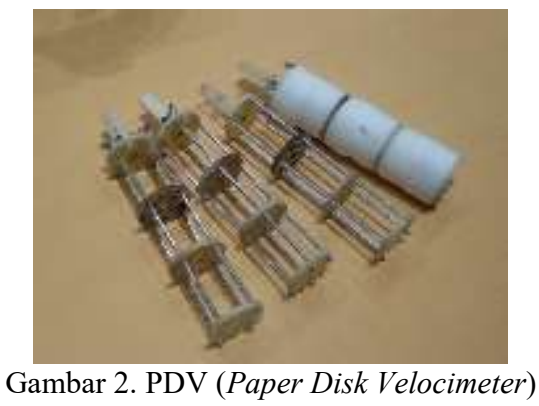

\section{METODOLOGI PENELITIAN}

\section{Lokasi Penelitian}

Dalam melakukan penelitian ini, pengukuran aliran air tanah dilakukan langsung di lapangan. Lokasi penelitian di Desa Meskom, Kecamatan Bengkalis, Kabupaten Bengkalis. Area sekitar penelitian dapat dideskripsikan dengan lokasi perkebunan sawit, kanal - kanal ada yang masih dialiri dan lainnya hanya digenangi air. Sebelumnya, tepat di wilayah sekitar lokasi penelitian pernah dilakukan analisis menggunakan data citra satelit mengenai laju abrasi dengan hasil laju abrasi pantai lebih dari $30 \mathrm{~m} /$ tahun yang dilakukan oleh Sigit Sutikno, Sandhyavitri, Haidar, \& Yamamoto (2017).

Area sekitar lokasi penelitian sangat sangat dekat dengan garis pantai (Gambar 3) yang mana terjadi fenomena abrasi. Sehingga dapat dikatakan lokasi tersebut merupakan lokasi yang strategis dilakukannya penelitian. Karena hal tersebut lokasi ini dijadikan sebagai lokasi penelitian. Pada titik titik peninjauan pengukuran aliran air tanah dilakukan dengan membuat sumur pantau dengan jarak terhadap garis pantai pada titik $1 \pm 380 \mathrm{~m}$ dan titik $2 \pm 280$ m dapat dilihat pada Gambar 4 .

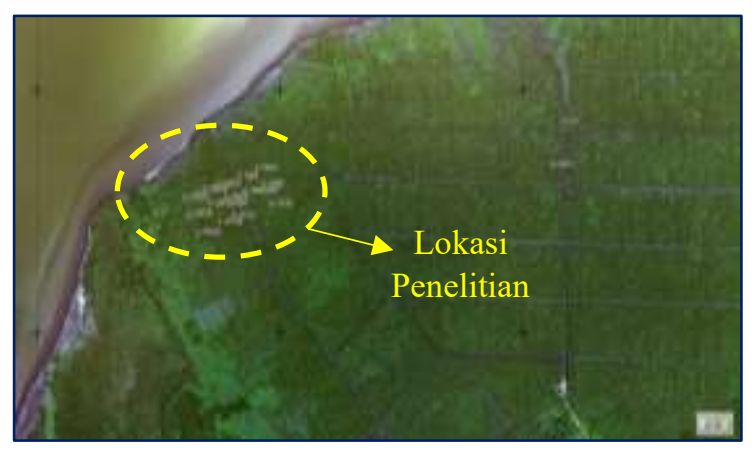

Gambar 3. Lokasi Penelitian

Sumber : (Aerial Photometry di Lokasi Penelitian oleh Yamamoto) 


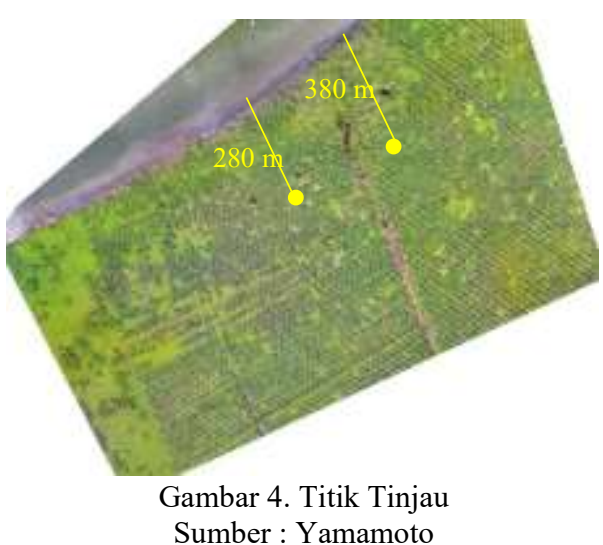

\section{Metode Penelitian}

Metode yang dilakukan untuk melakukan penelitian ini dengan metode pengamatan langsung di lapangan. Pengamatan dilakukan di 2 titik tinjauan dengan pengamatan kecepatan aliran dengan masing - masing titik pada kedalaman $2 \mathrm{~m}, 3 \mathrm{~m}$ dan $4 \mathrm{~m}$, sedangkan yang lain $2 \mathrm{~m}$ dan $5,5 \mathrm{~m}$. Perbedaan kedalaman masing - masing titik dikarenakan perbedaan kedalaman gambut pada kedua titik dan kendala yang terjadi di lapangan.

Penelitian dilakukan pada bulan 3 November 2019 dengan 3 kali pengamatan dalam 1 hari, yang mana dalam 1 kali pengamatan dilakukan selama 60 menit. dalam 1 kali pengamatan akan terdapat 3 nilai kecepatan dan arah aliran yang selanjutnya akan dilakukan analisis restultan kecepatan terhadap arah aliran.

\section{Tahapan Penelitian}

\section{Peralatan penelitian}

Peralatan dan Bahan yang Digunakan pada Penelitian

No Alat dan Bahan $\quad$ Fungsi

\begin{tabular}{|c|c|c|}
\hline 1. & Bor Gambut & $\begin{array}{l}\text { Membuat lubang } \\
\text { pada titik tinjau } \\
\text { sumur pantau }\end{array}$ \\
\hline 2. & $\begin{array}{l}\text { Pipa PVC Ø 2” dan } \\
\varnothing 1,5 "\end{array}$ & $\begin{array}{l}\text { Sebagai sumur } \\
\text { pantau }\end{array}$ \\
\hline 3. & $\begin{array}{l}\text { Penutup Pipa Ø2” } \\
\text { dan Ø1,5” }\end{array}$ & $\begin{array}{l}\text { Menutup dasar } \\
\text { sumur pantau }\end{array}$ \\
\hline 4. & Alat Bor & $\begin{array}{l}\text { Mengebor lubang } \\
\text { - lubang pada pipa }\end{array}$ \\
\hline 5. & Tiang & $\begin{array}{l}\text { Memasukkan } \\
\text { sensor ke dalam } \\
\text { sumur pantau }\end{array}$ \\
\hline 6. & $\begin{array}{l}\text { Kertas yang dibuat } \\
\text { dari Maruman } \\
\text { Company } 126,5 \mathrm{~g} / \mathrm{m}^{2} \\
\text { dan tinta hitam: } \\
\text { Canon BCl-6BK }\end{array}$ & $\begin{array}{l}\text { Menunjukkan hasil } \\
\text { arah dan kecepatan } \\
\text { aliran }\end{array}$ \\
\hline 7. & Sensor PDV & $\begin{array}{l}\text { Meletakkan spons } \\
\text { dan kertas }\end{array}$ \\
\hline
\end{tabular}

\begin{tabular}{|c|c|c|}
\hline 8. & Spons & $\begin{array}{l}\text { Menjaga } \\
\text { konsistensi aliran }\end{array}$ \\
\hline 9. & $\begin{array}{l}\text { Water Level } \\
\text { Mearsurement }\end{array}$ & $\begin{array}{l}\text { Mengukur muka } \\
\text { air tanah }\end{array}$ \\
\hline 10. & RTK - GPS & $\begin{array}{l}\text { Menentukan titik } \\
\text { untuk pemetaan } \\
\text { profil arah aliran }\end{array}$ \\
\hline 11. & Kompas & $\begin{array}{l}\text { Menunjukkan arah } \\
\text { utara sebagai patok } \\
\text { kertas penunjuk } \\
\text { arah aliran }\end{array}$ \\
\hline 12. & Drone & $\begin{array}{l}\text { Untuk aerial } \\
\text { photometry di } \\
\text { wilayah lokasi } \\
\text { penelitian }\end{array}$ \\
\hline
\end{tabular}

\section{Pengamatan aliran air tanah dengan PDV}

Pengukuran kecepatan aliran air tanah dilakukan pada sumur pantau yang sudah dibuat pada kedalaman tertentu. Pengukuran dilakukan pada daerah pinggi pantai yang mana pinggir pantai tersebut titik yang sering terjadinya abrasi. Berikut cara kerja pengukuran aliran air tanah dengan Paper Disk Velocimeter (Gambar 5) pada lahan gambut :

1. Meletakkan 3 bagian kertas (atas, tengah dan bawah) pada setiap titik pengukuran aliran.

1. Tinta pada kertas akan terjadi penyebaran sesuai Meletakkan 3 bagian kertas (atas, tengah dan bawah) pada setiap titik pengukuran aliran.

2. Tinta pada kertas akan terjadi penyebaran sesuai arah aliran yang dilalui

3. Setelah didapat sebaran tinta pada ketiga kertas, diambil hasil penyebaran yang paling dominan dari segi arah dan panjang sebaran.

4. Jika ketiga kertas mempunyai arah yang berbeda, maka hasil yang diambil adalah sebaran tinta yang terjelas dan terpanjang.

5. Jika tidak ada penyebaran tinta yang terjadi, maka tidak ada aliran yang terjadi.

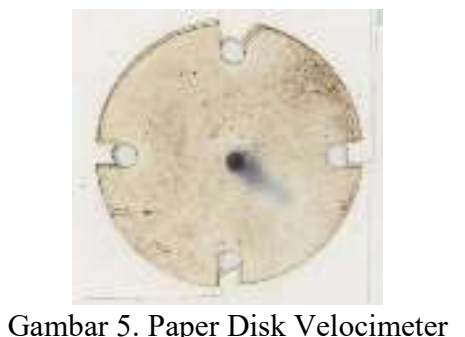

\section{Pengukuran Lapangan}

\section{Instalasi alat sumur pantau}

Sumur pantau berfungsi sebagai titik melakukan pengamatan untuk mengukur aliran air tanah dengan memasukkan sensor PDV. Sumur pantau yang digunakan terbuat dari pipa PVC dengan diameter 2"(inch). Titik peninjauan terdapat 2 titik dengan masing - masing menggunakan 2 sumur pantau dan lainnya 3 sumur pantau. Pada instalasi sumur pantau, 
setiap ujung pipa di bagian bawah ditutup dengan penutup pipa agar pada saat memasukkan pipa tidak ada material tanah yang masuk ke dalam pipa yang dapat mengganggu pengamatan. Berikut tahapan untuk pemasangan alat sumur pantau :

1. Tahap pertama memastikan titik tinjau yang sudah direncanakan dengan GPS

2. Melakukan pengeboran dengan bor gambut pada titik tinjau.

3. Memasukkan pipa PVC ke dalam lubang dengan panjang pipa yang sudah direncanakan sebelumnya sesuai kedalaman tertentu.

4. Biarkan sumur pantau 2 hingga 3 hari agar muka air tanah dalam sumur pantau sama dengan muka air tanah yang sebenarnya.

Berikut gambar sumur pantau di lapangan dapat dilihat pada Gambar 6.

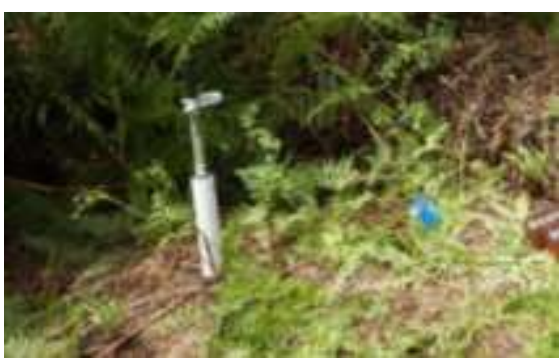

Gambar 6. Sumur Pantau

\section{Pengukuran kecepatan aliran}

Berikut tahapan pengukuran kecepatan aliran dengan pemasangan alat PDV yang dilakukan seperti pada Gambar 7 berdasarkan penelitian terdahulu :

1. Memasukkan sensor pada setiap lubang dengan tiap sensor terdapat 3 kertas (atas, tengah dan bawah) dan menentukan arah utara titik tinjau agar mengetahui arah aliran.

2. Biarkan sensor melakukan pengukuran selama 60 menit dan mengangkat kembali sensor ke atas permukaan secara perlahan.

3. Mengambil kertas setiap bagian dan melakukan pengukuran pergeseran tinta dan melihat arah aliran dengan pengukuran imageJ dan dapat juga melakukan dengan pengukuran manual guna mendapat arah dan kecepatan aliran air tanah.

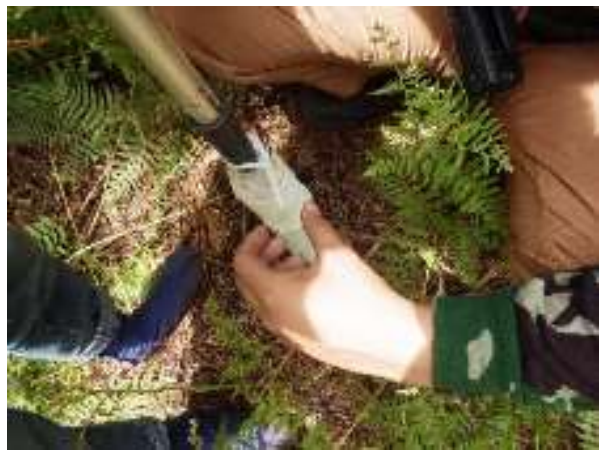

Gambar 7. Memasukkan Sensor PDV ke dalam Sumur Pantau

\section{Tahapan Pengolahan Data}

Tahapan pengolahan data yang didapat setelah dari pengukuran di lapangan :

1. Biarkan kertas hingga kering.

2. Selanjutnya melakukan scanning kertas dalam bentuk format gambar.

3. Pengukuran kecepatan aliran air tanah serta arah aliran air tanah dengan software ImageJ.

4. Selanjutnya analisis nilai yang didapat dari ImageJ dengan beberapa persamaan berikut.

a. Persamaan dalam pengukuran sudut atau arah aliran air tanah (persamaan 1).

$\varnothing$

$$
=\operatorname{arc} \operatorname{Tan}\left(\frac{Y M d o t-Y M \text { Tailing }}{X M d o t-X M \text { Tailing }}\right)
$$

b. Persamaan dalam pengukuran kecepatan aliran air tanah (persamaan 2).

$$
\begin{gathered}
\text { Kecepatan } 60 \mathrm{mnt}=\frac{1}{10,761} \times 0,1 \times((\mathrm{XM} d o t-\mathrm{XM} \\
\text { Tailing } \left.)^{2}+(\mathrm{YM} \text { dot }-\mathrm{YM} \text { Tailing })^{2}\right)^{0,5}
\end{gathered}
$$

c. Persamaan yang digunakan dalam menentukan resultan dari kecepatan aliran air tanah (persamaan 3).

$$
\mathrm{Vr}=\sqrt{\mathrm{Vxi}^{2}+\mathrm{Vyi}^{2}}
$$

\section{Analisis Data}

\section{Analisis kecepatan aliran air tanah}

Dalam melakukan tahap analisis aliran air tanah digunakan software ImageJ. Hasil dari pengukuran lapangan dari PDV selanjutnya dilakukan scanning menggunakan scanner Epson GT-X830. Ditampilkan salah satu hasil scanning dari PDV pengukuran pertama kedalaman 2 meter dengan kertas pada sisi tengah sensor. Berikut tahapan pengolahan data analisis kecepatan dan arah aliran air tanah (Gambar $8-12)$.

1. Hasil scanning PDV dengan format gambar.

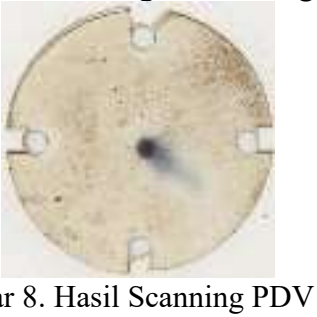

2. Memasukkan gambar ke software ImageJ.

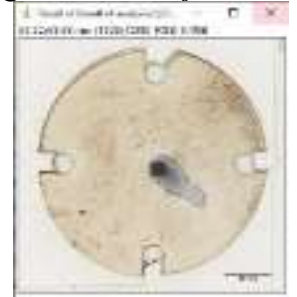

Gambar 9. Input Hasil Scanning ke ImageJ 
3. Melakukan running dengan menggunakan macro processing pada ImageJ.

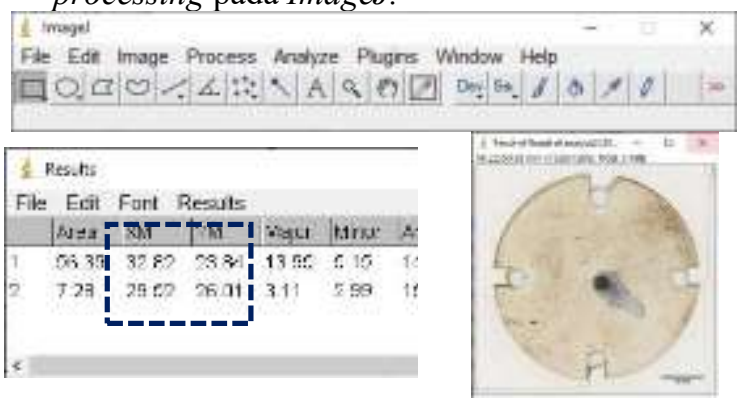

Gambar 10. Hasil Running Gambar dengan ImageJ

4. Hasil running berupa data makro selanjutnya copy ke Microsoft Office Excel yang sudah terformat dengan rumus pengolahan data untuk menemukan sudut atau arah dan kecepatan aliran air tanah.

\begin{tabular}{|c|c|c|c|c|}
\hline 19163 & bottom & November 3rd & 110,7 & 110,7 \\
\hline -ーーー & ーーーーーー & 1ーーーーーーー & -ーーーー & ーーーーーーー \\
\hline 19208 & middle & November 3rd & 123,5 & 123,5 \\
\hline LEr & 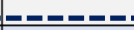 & . & ב & \\
\hline 19174 & top & November 3rd & 152,6 & 152,6 \\
\hline
\end{tabular}

Gambar 11. Nilai Sudut Arah Aliran Terhadap Utara aliran :

Berikut contoh perhitungan sudut atau arah

$$
\begin{aligned}
& \varnothing \quad=\operatorname{arc} \operatorname{Tan}\left(\frac{\mathrm{XM} \text { dot-XM Tailing }}{\text { YM dot-YM Tailing }}\right) \\
& =\operatorname{arc} \operatorname{Tan}\left(\frac{29,52-32,82}{26,01-23,84}\right) \\
& =\operatorname{arc} \operatorname{Tan}\left(\frac{-3,3}{2,17}\right) \quad \text { (kuadran II) } \\
& =-56,5^{\circ}+180^{\circ}=123,5^{\circ}
\end{aligned}
$$

Berikut contoh perhitungan kecepatan aliran air tanah dari hasil analisis menggunakan software ImageJ :

Kec. Aliran/60 menit

$=\frac{1}{10,761} \mathrm{x} 0,1 \mathrm{x}\left((\mathrm{XM} d o t-\mathrm{XM} \text { Tailing })^{2}+(\mathrm{YM} d o t-\right.$ YM Tailing) $\left.)^{2}\right)^{0,5}$

\begin{tabular}{|c|c|c|c|c|}
\hline $2 m$ & bottom & $10: 23$ & 0,01182 & 0,17025 \\
\hline rar & - & -ேே-ே & 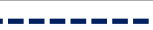 & 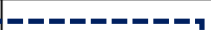 \\
\hline $2 m$ & middle & $10: 23$ & 0,03601 & 0,51849 \\
\hline LEー & . & -ேーー & 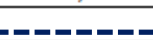 & | \\
\hline $2 m$ & top & $10: 23$ & 0,02993 & 0,43092 \\
\hline
\end{tabular}

$=\frac{1}{10,761} \times 0,1 \times\left((29,52-32,83)^{2}+(26,01-23,84)^{2}\right)^{0,5}$

$=0,03601 \mathrm{~cm} /$ menit

$=0,03601 \times \frac{24 \times 60}{100} \quad=0,51489 \mathrm{~m} / \mathrm{hari}$

Gambar 12. Input Data untuk Menghitung Kecepatan

$$
\text { Aliran }
$$

\section{Analisis resultan arah dan kecepatan aliran air tanah}

Setelah dilakukan analisis arah dan kecepatan aliran, didapat banyak data kecepatan dan arah aliran pada 1 titik dan kedalaman yang sama dengan arah dan kecepatan yang berbeda. Untuk menentukan arah dan kecepatan aliran yang dapat digunakan sebagai hasil, maka dilakukan analisis berikutnya yaitu menentukan resultan dari arah dan kecepatan aliran air tanah tersebut. Berikut langkah - langkah yang digunakan dalam melakukan analisis dengan metode vektor.

1. Menentukan arah dan kecepatan aliran air tanah yang dapat digunakan karena tidak semua nilai dapat digunakan. Berikut syarat - syarat untuk pemilihan arah dan kecepatan aliran :

a. Batas kecepatan aliran air tanah $>0,01$ $\mathrm{cm} / \mathrm{menit}$

b. Gunakan nilai terbesar pada setiap pengujian

c. Priotitaskan kertas pada sisi tengah sensor terlebih dahulu

d. Perhatikan arah aliran terhadap kontur muka air tanah

e. Jika hanya 1 pengukuran yang memenuhi persyaratan 1 dan 2 maka nilai tersebut dapat digunakan sebagai nilai dari arah dan kecepatan aliran air tanah.

2. Selanjutnya, menghitung resultan arah dan kecepatan aliran pada kedalaman yang sama dengan waktu pengukuran yang berbeda. Berikut contoh perhitungan menentukan nilai resultan pada titik N2C dengan kedalaman 2 meter pengukuran menggunakan metode vector dengan skema pada Gambar 13.

Tabel 1. Data PDV Kedalaman $2 \mathrm{~m}$ di Titik N2C

\begin{tabular}{|c|c|c|c|}
\hline \multicolumn{2}{|c|}{ Arah $\left(^{\circ}\right)$} & \multicolumn{2}{c|}{$\alpha$ terhadap sumbu X $\left(^{\circ}\right)$} \\
\hline I & II & I & II \\
\hline 123,5 & 168,8 & $\begin{array}{c}33,5 \\
\text { (kuadran II) }\end{array}$ & $\begin{array}{c}78,8 \\
\text { (kuadran II) }\end{array}$ \\
\hline \multicolumn{2}{|c|}{ Nilai } & \multicolumn{2}{c|}{ Kecepatan/V (cm/menit) } \\
\hline Sin & Cos & V1 & V1 \\
\hline 0,552 (I) & 0,834 (I) & 0,03601 & 0,02008 \\
\hline 0,981 (II) & 0,194 (II) & \\
\hline
\end{tabular}




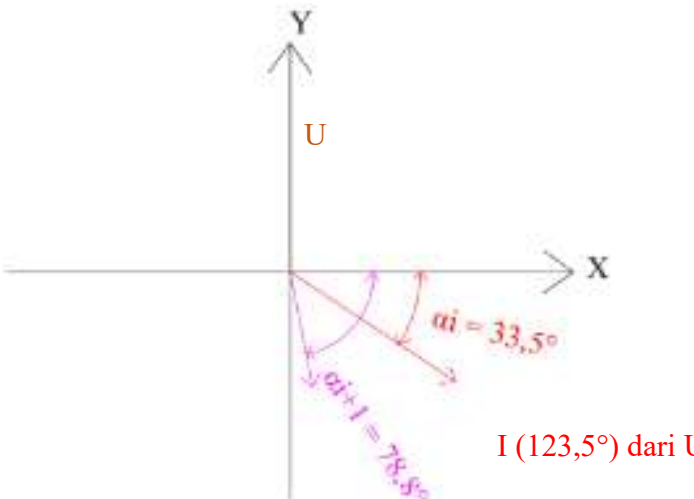

Gambar 13. Skema Arah Allrah68,8) dari U

Berikut persamaan dan contoh perhitungan yang digunakan dalam menetukan resultan kecepatan aliran air tanah.

$$
\begin{aligned}
& \mathrm{Vxi}=\mathrm{Vi} * \operatorname{Cos} \alpha \mathrm{i} \\
& \mathrm{Vyi}=\mathrm{Vi} * \operatorname{Sin} \alpha \mathrm{i} \\
& \begin{array}{c|c}
\mathrm{X} & \mathrm{Y} \\
0,03601 * 0,834= & -0,03601 * 0,552=
\end{array} \\
& 0,0300 \quad-0,0199 \\
& \text { V2 } \\
& 0,02008 * 0,195=\quad-0,02008 * 0,981= \\
& \begin{array}{c|r}
0,0039 & -0,0197 \\
\hline V x=0,0339 & V y=-0,0396
\end{array} \\
& \mathrm{Vr}(\text { resultan }) \quad=\sqrt{\mathrm{Vxi}^{2}+\mathrm{Vyi}^{2}} \\
& \mathrm{Vr} \quad=\sqrt{(0,0339)^{2}+(-0,0396)^{2}} \\
& =0,0521 \mathrm{~cm} / \text { menit } \\
& =0,7507 \mathrm{~m} / \text { hari }
\end{aligned}
$$

Selanjutnya, menghitung arah aliran air tanah dengan persamaan berikut.

$$
\begin{aligned}
\varnothing\left(^{\circ}\right) & =\operatorname{Tan}^{-1} \frac{\mathrm{Vyi}}{\mathrm{Vxi}} \\
& =\operatorname{Tan}^{-1} \frac{-0,0396}{0,0339} \\
& =49,41^{\circ} \text { (kuadran II) }
\end{aligned}
$$

Maka, arah aliran yang sebenarnya adalah $90^{\circ}+$ $49,41^{\circ}=\underline{139,41^{\circ}}($ Gambar 14$)$

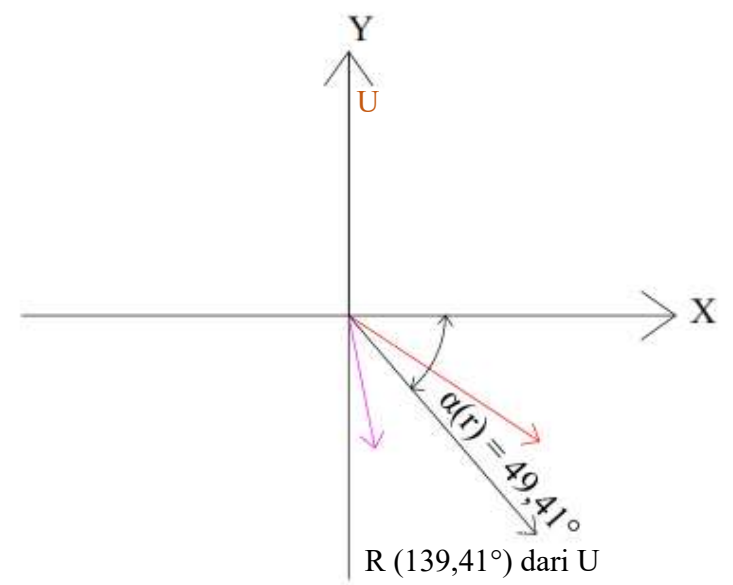

Gambar 14. Resultan Arah Aliran

\section{HASIL DAN PEMBAHASAN}

Berikut merupakan hasil dari semua kecepatan dan arah aliran air tanah yang memenuhi persyaratan, yang mana selanjutnya sebagai nilai yang digunakan sebagai resultan kecepatan dan arah aliran air tanah. Nilai tersebut dapat dilihat pada Tabel 2.

Tabel 2.Nilai Kecepatan

\begin{tabular}{|c|c|c|c|c|}
\hline \multirow{3}{*}{ Titik } & \multirow{2}{*}{ Kedalaman } & \multirow{2}{*}{$\begin{array}{c}\text { Posisi } \\
\text { Kertas }\end{array}$} & $\begin{array}{c}\text { Arah } \\
\text { Aliran }\end{array}$ & $\begin{array}{c}\text { Kecepatan } \\
\text { Aliran }\end{array}$ \\
\cline { 3 - 5 } & meter & & $\left.{ }^{\circ}\right)$ & $(\mathrm{cm} / \mathrm{mnt})$ \\
\hline \multirow{4}{*}{ N2C } & \multirow{2}{*}{2} & Tengah & 123,5 & 0,0360 \\
\cline { 3 - 5 } & \multirow{3}{*}{5} & Atas & 168,8 & 0,0201 \\
\cline { 3 - 5 } & \multirow{3}{*}{ N2W2 } & Atas & 28,8 & 0,0120 \\
\cline { 3 - 5 } & & Atas & 5,9 & 0,0340 \\
\cline { 3 - 5 } & \multirow{2}{*}{3} & Tengah & 216,9 & 0,0203 \\
\cline { 3 - 5 } & \multirow{3}{*}{3} & Bawah & 353,0 & 0,0296 \\
\cline { 3 - 5 } & & Tengah & 149,5 & 0,0215 \\
\cline { 3 - 5 } & & Tengah & 163,0 & 0,0138 \\
\cline { 3 - 5 } & \multirow{2}{*}{4} & Atas & 165,3 & 0,0203 \\
\cline { 3 - 5 } & & Atas & 138,2 & 0,0344 \\
\cline { 3 - 5 } & & Tengah & 137,5 & 0,0214 \\
\hline
\end{tabular}

Setelah mendapat nilai - nilai kecepatan dan arah aliran air tanah, dilakukan analisis resultan kecepatan dan arah aliran. Berikut hasil dari nilai resultan dapat dilihat pada Tabel 3.

Tabel 3. Resultan Kecepatan

\begin{tabular}{|c|c|c|c|c|}
\hline \multirow{2}{*}{ Titik } & \multirow{2}{*}{ Kedalaman } & $\begin{array}{c}\text { Arah } \\
\text { Aliran }\end{array}$ & \multicolumn{2}{c|}{ Kecepatan Aliran } \\
\cline { 2 - 5 } & meter & $\left({ }^{\circ}\right)$ & $\mathrm{cm} / \mathrm{mnt}$ & $\mathrm{m} /$ hari \\
\hline \multirow{2}{*}{ N2C } & 2 & 139,41 & 0,0521 & 0,7507 \\
\cline { 2 - 5 } & 5.5 & 354,06 & 0,0282 & 0,4067 \\
\hline \multirow{3}{*}{ N2W2 } & 2 & 125,19 & 0,0153 & 0,2210 \\
\cline { 2 - 5 } & 3 & 101,71 & 0,0116 & 0,1665 \\
\cline { 2 - 5 } & 4 & 145,14 & 0,0744 & 1,0714 \\
\hline
\end{tabular}

\section{KESIMPULAN}

Arah alian air tanah dari hasil yang didapat sangat bervariasi dan acak. Hal ini terjadi akibat adanya gaya kapiler pada aliran dimana aliran dapat bergerak ke segala arah. Diduga hal ini dampak dari tanah itu sendiri sebagaimana bahan pembentuk gambut yang berserat dan halus. Dari nilai kecepatan yang didapat disimpulkan bahwa tidak selalu nilai kecepatan aliran berbanding terbalik dengan kedalaman. Dapat dilihat dari nilai kecepatan yang tertinggi pada titik N2W2 di kedalaman $4 \mathrm{~m}$ mencapai $1,07 \mathrm{~m} /$ hari dengan arah aliran $145,14^{\circ}$ terhadap arah utara.

Adapun saran dari penelitian ini yaitu kepada peneliti - peneliti berikutnya yang menggunakan PDV sebagai alat pengukur kecepatan aliran air tanah yang juga parameter untuk mengukur permeabilitas 
tanah serta lebih menggaungkan pengenalan alat ini agar dikenal lebih luas.

\section{DAFTAR PUSTAKA}

[1] Masganti, Wahyunto, A. Dariah, Nurhayati, and R. Yusuf, "Karakteristik dan Potensi Pemanfaatan Lahan Gambut Terdegradasi di Provinsi Riau," pp. 59-66, 2014.

[2] R. Sahputra, S. Sutikno, and A. Sandhyavitri, "Mitigasi Bencana Kebakaran Lahan Gambut Berdasarkan Metode Network Analysis Berbasis Gis (Studi Kasus: Pulau Bengkalis)," Jom FTEKNIK, vol. 4, no. 2, pp. 1-11, 2017.

[3] S. Sutikno, Saldanela, and A. Hendri, "Pemetaan Pola Aliran Air Tanah Berbasis Sistem Informasi Geografis (Sig) Di Kawasan Kecamatan Tampan Kota Pekanbaru," Aliran Air Tanah, vol. 1, no. 1, pp. 1-8, 2017.

[4] S. Sutikno, R. D. Ramawilis, F. A. Hutapea, Rinaldi, and K. Yamamoto, "Application of paper disc velocimeter for groundwater flow measurement in tropical peatland," 9th AIC 2019 Sci. Eng., 2020.

[5] S. Sutikno, A. Sandhyavitri, M. Haidar, and K. Yamamoto, "Shoreline Change Analysis of Peat Soil Beach in Bengkalis Island Based on GIS and RS," vol. 9, no. 3, pp. 233-238, 2017. 